\title{
Selenium protects cerebral cells by cisplatin induced neurotoxicity ${ }^{1}$
}

\author{
Ergun Karavelioglu', Mehmet Gazi Boyaci' ${ }^{I I}$, Nejdet Simsek ${ }^{\mathrm{III}}$, Mehmet Akif Sonmez ${ }^{\mathrm{IV}}$, Rabia Koc ${ }^{\mathrm{V}}$, Mustafa Karademir ${ }^{\mathrm{VI}}$, \\ Mustafa Guven ${ }^{\text {III }}$ Olcay Eser ${ }^{\text {VIII }}$
}

DOI: http://dx.doi.org/10.1590/S0102-865020150060000004

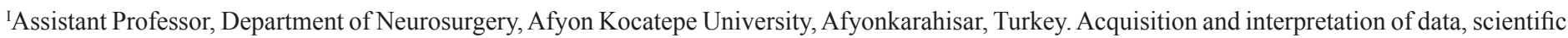
and intellectual content of the study, manuscript writing.

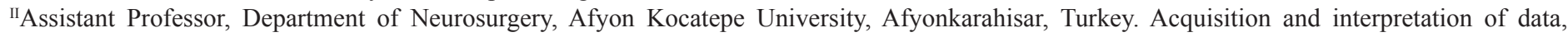
manuscript writing.

IIIAssociate Professor, Department of Histology and Embryology, Balikesir University, Balikesir, Turkey. Histopathological examinations, conception and design of the study.

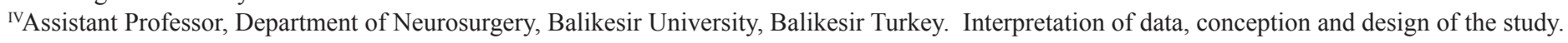
${ }^{v}$ Assistant Professor, Department of Neurology, Balikesir University, Balikesir Turkey. Interpretation of data.

${ }^{\mathrm{VI} M D}$, Department of Neurosurgery, Afyonkarahisar State Hospital, Afyonkarahisar, Turkey. Interpretation of data.

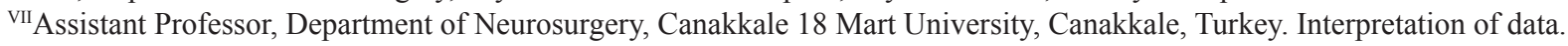

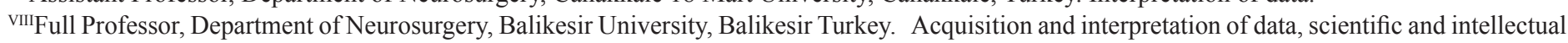
content of the study.
\end{abstract}

\section{ABSTRACT}

PURPOSE: To evaluate the central nervous system toxicity of cisplatin and neuroprotective effect of selenium.

METHODS: Twenty-one male Wistar albino rats were divided into three groups: control (C), cisplatin (CS), cisplatin and selenium (CSE, $\mathrm{n}=7$ in each group). Cisplatin ( $12 \mathrm{mg} / \mathrm{kg} / \mathrm{day}$, i.p.) was administered to CS and CSE groups for three days. Furthermore, CSE group received $3 \mathrm{mg} / \mathrm{kg} / \mathrm{day}$ (twice-a-day as $1.5 \mathrm{mg} / \mathrm{kg}$ ) selenium via oral gavage five days before cisplatin injection and continued for 11 consecutive days. The same volumes of saline were administered to $\mathrm{C}$ group intraperitoneally and orally at same time.

RESULTS: Heterochromatic and vacuolated neurons and dilated capillary vessels in the brain were observed in the histochemical examinations of cisplatin treated group. Rats that were given a dose of $3 \mathrm{mg} / \mathrm{kg} / \mathrm{day}$ selenium decreased the cisplatin induced histopathological changes in the brain, indicating a protective effect. In addition, cytoplasmic staining of the cell for bcl-2, both cytoplasmic and nuclear staining for bax were determined to be positive in the all groups. Bax positive cells were increased in the CS group compared to $\mathrm{C}$ group, in contrast to decreased bcl-2 positivity.

CONCLUSION: Selenium limited apototic activity and histological changes due to the cisplatin related central neurotoxicity.

Key words: Cisplatin. Selenium. Neurotoxicity. Rats. 


\section{Introduction}

Cisplatin (cis-diamminedichloroplatinum II; Cis), a platinum based alkylating potent anticancer drug, is widely used in many types of cancers such as testicular, ovarian, colorectal, lung, breast, head and neck cancers ${ }^{1-4}$. However, use of cisplatin in tumor therapy has some harmful effects which can be detected virtually on all tissues. Some side effects of cisplatin exposure are auditory toxicity, nephro-toxicity, cardio-toxicity, gonado-toxicity, hepato-toxicity, ototoxicity, central and peripheral neurotoxicity ${ }^{5,6}$. Neurotoxicity induced by cisplatin is one of the most important dose limiting toxicities. Studies have revealed that up to $30 \%$ of patients given cisplatin have neurotoxicities ${ }^{7}$. Furthermore, numerous studies have shown that cisplatin increases the rate of apoptotic cell death.

Selenium is an essential trace element and taken in very low levels by diet. It shows antioxidant and neuroprotective effects by scavenging free oxygen radicals. Selenium is a cofactor for glutathione peroxides (GPx) and protects DNA, lipids and protein by reducing hydro peroxides and lipoperoxidases ${ }^{8,9}$. Selenium is also an important component of several selenoproteins which are expressed in brain. Many previous studies reported that selenium has a neuroprotective effect ${ }^{10-12}$.

Currently many chemo protective agents such as erythropoietin, fish oil, valproate, vitamin E, melatonin and alpha lipoic acid were used to reduce or prevent the neurotoxic effect of the cisplatin in various in vivo and in vitro studies through different cellular targets ${ }^{13-18}$. However, to our knowledge, there is not any previous study which investigated whether selenium can reduce or prevent cisplatin induced central neurotoxicity.

In the present study, we aimed to evaluate whether selenium can reduce cisplatin induced neurotoxicity in an animal model. Within this context, the putative histopathological and immunohistochemical changes were evaluated in brain of the rats.

\section{Methods}

Study protocols and experimental methods were approved by the local Institutional Ethics Committee of Experimental Animals (Approval number: 2013-13-94; approval date: July 3, 2013) and the experiments were performed according to the National Institutes of Health (NIH) guidelines on animal use. In total of 21 adult male Wistar-Albino rats, weighing 280 $300 \mathrm{~g}$ were randomly divided into three groups of seven rats each: Group C (Control, n=7), Group CS (Cisplatin, n=7), Group CSE (Cisplatin+ Selenium, $\mathrm{n}=7$ ).
Cisplatin (Sigma-Aldrich Co, Germany) was administered to the rats in CS and CSE groups at a dose of $12 \mathrm{mg} / \mathrm{kg}$ body weight/day, intraperitoneally for 3 consecutive days ${ }^{19,20}$. In addition to cisplatin, rats in CSE group were given $3 \mathrm{mg} / \mathrm{kg}$ body weight/ day selenium (Sodium selenite, Sigma-Aldrich Co., Germany) by oral gavage twice-a-day as $1.5 \mathrm{mg} / \mathrm{kg}^{21,22}$ for 11 consecutive days starting at five days prior to cisplatin administration. On the other hand, $\mathrm{C}$ group received intraperitoneal and oral saline at same volume and at same time. All of the rats were maintained in a $12-\mathrm{h}$ light/dark cycle environment (lights on between 7:00-19:00 h) at a temperature of $22 \pm 1^{\circ} \mathrm{C}$ and $50 \%$ humidity. Rats had access to food and water ad libitum. At the end of experimental protocol, the animals were euthanized and right and left brain lobes were removed for histopathological and immunohistochemical examination.

\section{Histopathological and immunohistochemical analysis}

The cerebrum tissues fixed by $10 \%$ buffered formalin were dehydrated and embedded in paraffin and serial sections were cut using a microtome. The sections were stained with Crossman modified Mallory's triple staining for histopathological evaluations. In addition, photomicrographs were taken. Evaluations of the cerebrum for histopathologic changes and cerebral cortex structure were done under high-power light microscopic (Nikon Eclipse i50).

For immunohistochemical analysis, the cerebrum tissues were stained with bax which initiates apoptosis and with bcl2 which protects against apoptosis (Bax and bcl-2, Santa Cruz Biotechnology). For inhibition of endogenous peroxides activity, samples were treated with $0.3 \% \mathrm{H}_{2} \mathrm{O}_{2}$, and then incubated in $1 \%$ normal bovine serum to reduce non-specific binding sites. Bax and bcl-2 primary antibodies were incubated at $+4{ }^{\circ} \mathrm{C}$ temperature for 18 hours. These sections were incubated with biotinylated secondary antibody and streptavidin-HRP for 1 hour, and then 3,3'-diaminobenzidine tetrahydrochloride (DAB) substrate kits for 3-5 min to obtain immunolabelling. Finally, nuclei were counterstained with Mayer's haematoxylin.

Image analysis was performed using a personal computer, a camera, software (Kameram SLR, 1.6.1.0, Mikro Sistem, Ltd. Sti. Turkey) and an optical microscope. The number of bax and bcl-2 immunohistochemical positive cells in five randomly chosen microscopic fields was counted. These cell numbers were used to measure the balance between cell survival and cell death, and the bax/bcl-2 ratio was calculated by dividing the $\%$ of bax $(+)$ cells by the $\%$ of bcl- $2(+)^{23}$. 
In addition, the intensity of staining with antibodies was subjectively scored ${ }^{24}$ as follows:

$\mathrm{A}=$ Non-reactivity, $\mathrm{B}=$ Weak, individualized cell reactivity in $\leq 25 \%$ of cerebral cortex, $\mathrm{C}=$ Mild to moderate reactivity in $\leq 50 \%$ of cerebral cortex, $\mathrm{D}=$ Strong reactivity in $\leq 75 \%$ of cerebral cortex, $\mathrm{E}=$ Very strong reactivity in $>75 \%$ of cerebral cortex. The average staining intensity was calculated by the formula: $[(\mathrm{A} \times 1)+(\mathrm{B} \times 2)+(\mathrm{C} \times 3)+(\mathrm{D} \times 4)+(\mathrm{E} \times 5)] /(\mathrm{A}+$ $\mathrm{B}+\mathrm{C}+\mathrm{D}+\mathrm{E})$, and reported, as follows:
i) Not detected $(-) \quad=0.00$
ii) Rare
$(+) \quad=0.01-1.00$
iii) Small number
$(++) \quad=1.01-2.00$
iv) Moderate amount $\quad(+++) \quad=2.01-3.00$
v) High number $(++++)=3.01-4.00$

\section{Statistical analysis}

All values were expressed as mean \pm standard deviation. The numbers of bax and bcl-2 immunopositive cells were analyzed using a one-way analysis of variance (ANOVA). Significant differences among treatment means were determined by using Duncan's. Differences with a $\mathrm{p}<0.05$ were considered significant.

\section{Results}

\section{Histopathological evaluation}

In the $\mathrm{C}$ group; the layer of the cerebral cortex had normal histological appearances. Margins of neurons of the cerebrum were distinct and cell membrane integrity was preserved. Furthermore, nucleolus was distinctively observed and nucleolus margins were regular. In the CS group; most of the big pyramidal shaped neurons had heterochromatic nucleus and vacuolated area was shaped around the neurons. Dilatations of the capillary vessels were observed in the all layer of the cerebrum in the CS group. The structures of the squamous epithelium of the vascular endothelial cells were rounded and increased lumen diameter with oval-round shape was observed. Moreover, a few peripherally located neuroglia cells were detected around the neurons (Figure 1A). In the CSE group; markedly decreased the number of the heterochromatic cells and polarized neuroglia cell and decreased capillary lumen width were observed. Besides this the structures of the most capillary vessels lumen were similar to the structure of the control group capillary vessels (Figure 1B).

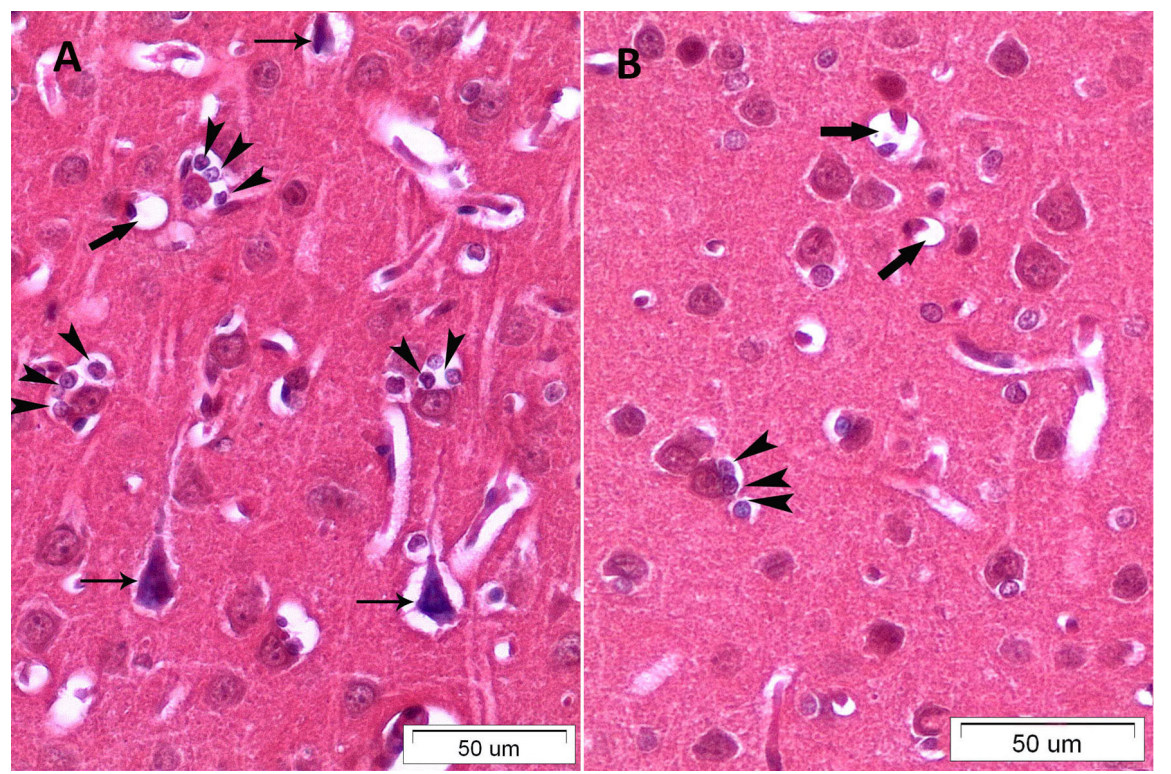

FIGURE 1 - A. CS group. B. CSE group, arrow heads: polarised neuroglia cell; arrows: apoptotic, vacuolised and heterochromatic pyramidal cells; bold arrows: dilated capillary.

\section{Immunohistochemical evaluation}

In the present study, for determination of apoptotic and antiapoptotic activities of the neurons, streptavidin-biotin peroxidase staining was used to detect bax and bcl-2 protein. The results of immunohistochemical staining were shown in Table 1.
Cytoplasmic staining of the cell for bcl-2, both cytoplasmic and nuclear staining for bax, were determined to be positive in the all groups. In the $\mathrm{C}$ group, bax $(+)$ reactions were rarely observed in the small pyramidal shaped neurons (Figure $2 \mathrm{~A}$ ), but bcl-2 positive cells were higher in all cortical neurons and rarely glial cells (Figure 2B). In the CS group, bax (+) reactions were observed higher in the 
cytoplasma and nucleus of the small and large pyramidal shaped neurons and were slightly reactions observed in the protoplasmic astrocytes and oligodendrocytes forming neuroglia tissue (Figure $3 \mathrm{~A})$. In addition, an increase was determined in bax/bcl-2 ratio in the CS group (2.72) when compared to the control (0.38) group. Both factors (decrease in antiapoptotic bcl-2 activity and increase in apoptotic bax activity) led this situation (Figure 3B). As Figures $4 \mathrm{~A}$ and $\mathrm{B}$ demonstrates, there was a trend for increase of bcl-2 and decrease for bax positive cell numbers in CSE group compared to CS group. The bax/bcl-2 ratio was evaluated as 1.16 in the CSE group. The analysis also shows a significant increase in the ratio cell survival according to CS group.

TABLE 1 - Histochemical, immunohistochemical and morphological examinations in the cerebral cortex.

\begin{tabular}{ccccc}
\hline Groups & Histopathological changes & Bax positivity & Bcl-2 positivity & Bax/Bcl-2 ratio \\
\hline C & - & $-/+$ & +++ & $26 \pm 2.4^{\prime 67 \pm 4.1^{\mathrm{c}}}$ \\
CS & +++ & ++++ & + & $68 \pm 1.3 / 25 \pm 2.7^{\mathrm{a}}$ \\
CSE & + & ++ & ++ & $56 \pm 1.7 / 48 \pm 2.9^{\mathrm{b}}$ \\
\hline
\end{tabular}

C: Control; CS: Cisplatin; CSE: Selenium

The scores reported are as follows: $-=$ not detected, $+=$ rare,$++=$ small number, $+++=$ moderate amount, $++++=$ high number .

Different superscripts a,b,c, in the same column indicate significant differences $(\mathrm{p}<0.05)$ according to the experimental groups.
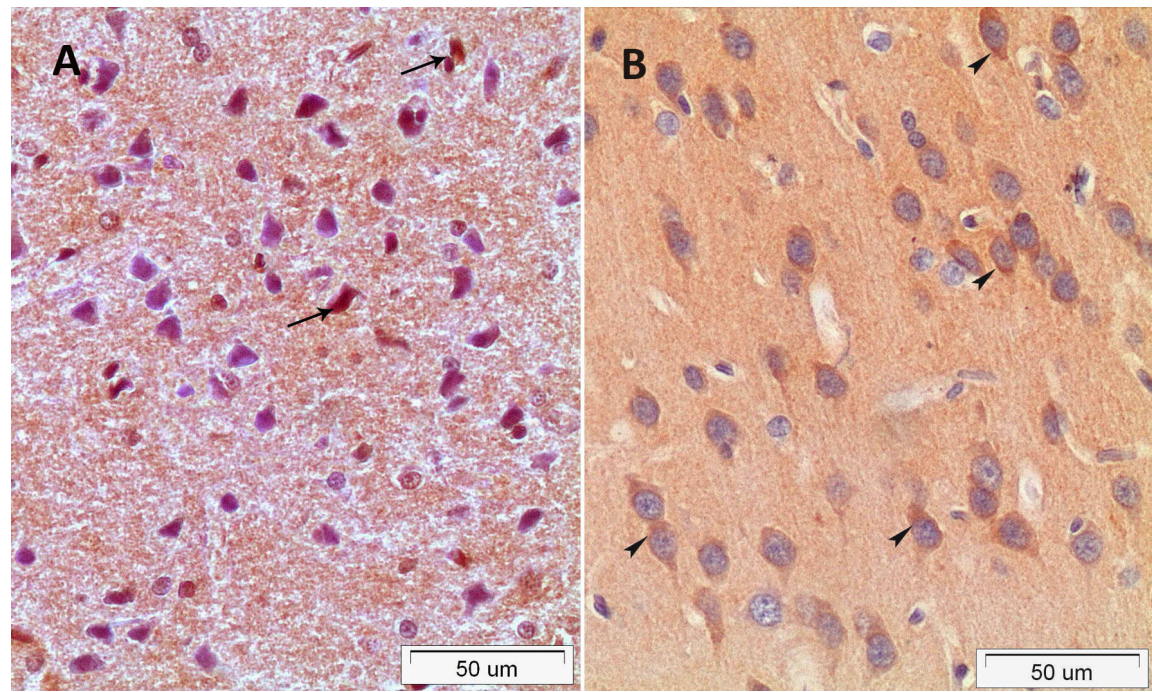

FIGURE 2 - A. Bax immunopositive cells. B. Bcl-2 immunopositive cells in the control group; arrows: bax positive apoptotic cells; arrow heads: Bcl positive cells.

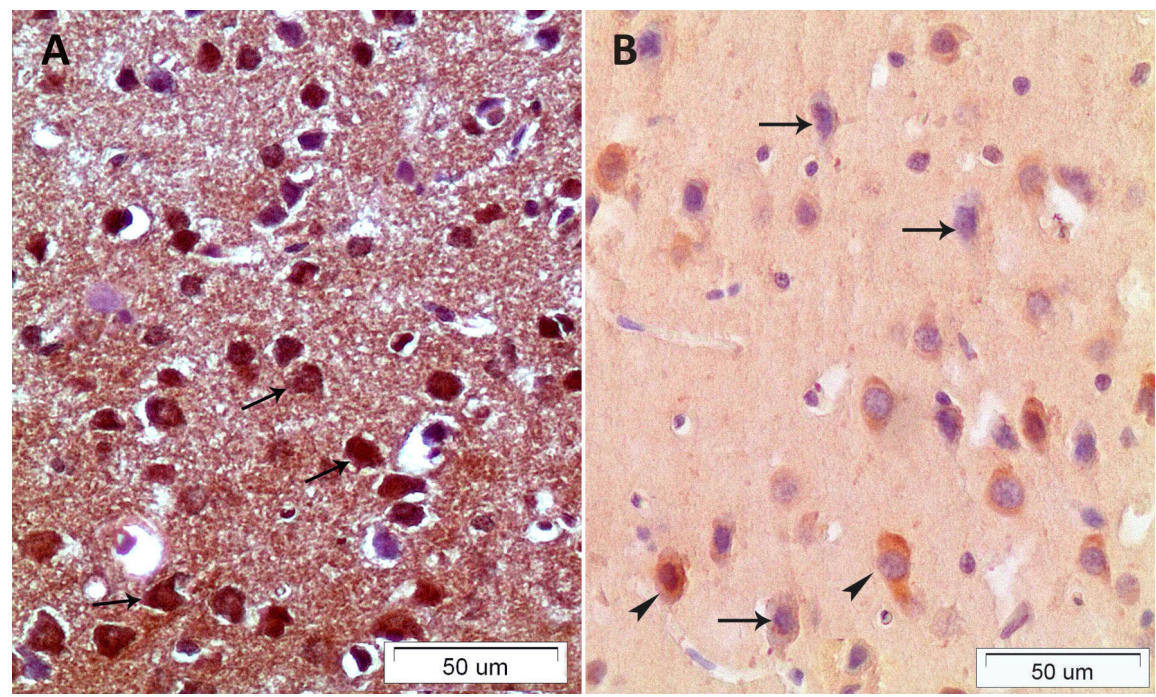

FIGURE 3 - A. Bax immunopositive cells in CS group; arrows: bax positive cells. B. Bcl-2 immunopositive cells in CS group; arrows: apoptotic cells; arrow heads: Bcl positive cells. 


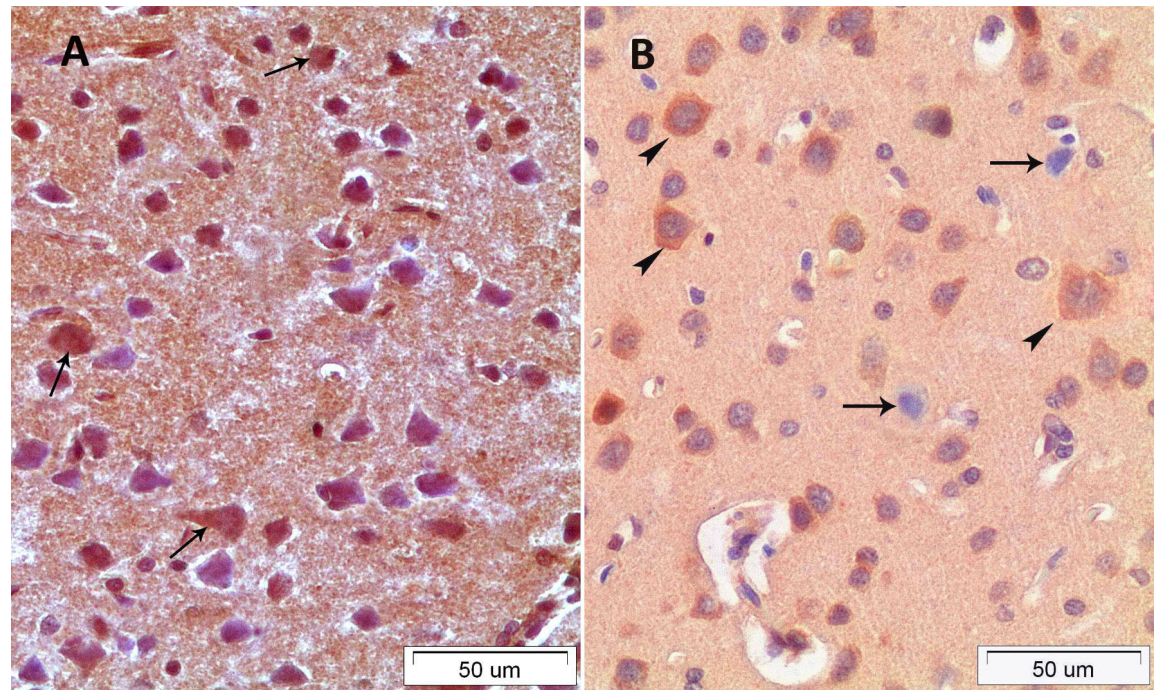

FIGURE 4 - A. Bax immunopositive cells in CSE group; arrows: bax positive cells. B. Bcl-2 immunopositive cells in CSE group; arrows: apoptotic cells, arrow heads: Bcl positive cells.

\section{Discussion}

Cisplatin is a very effective drug which is commonly used in the treatment of solid tumors such as colorectal, head and neck, ovarian, testicular, lung, breast, and bladder tumors. Due to the widespread side effects of cisplatin, its use is limited. Comprehensive neurologic and neurophysiologic examinations have revealed that all patients receiving cisplatin treatment with cumulative doses higher than $300 \mathrm{mg} / \mathrm{m}^{2}$ develop signs of neurotoxicity ${ }^{15}$. Cisplatin neurotoxicity including ototoxicity, peripheral sensory polyneuropathy and focal encephalopathy are among the most important dose limiting toxicities ${ }^{15,16}$. Many previous studies have focused on the neurotoxicity of cisplatin in peripheral neuropathy and effectiveness of chemo protective agents $^{6,18,25,26}$. Only a few studies have focused on central neurotoxicity of cisplatin ${ }^{13,27,28}$.

Dietrich et $a{ }^{28}$ showed that anti-cancer drugs (Carmustine, cisplatin and cytosine arabinoside) are severely toxic for the progenitor cells of the central nervous system and for non-dividing oligodentrocytes than for cancer cells. In addition, they reported that systemically administration of cisplatin increased the cell death and decreased cell division in the dentate gyrus of the hippocampus and in the corpus callosum. Another study conducted by Rzeski et al. ${ }^{27}$ reported that cisplatin was the second most neurotoxic anti-cancer drug after vinblastin with $30 \%$ neuronal death at $100 \mu \mathrm{M}$ and $100 \%$ neuronal death at 500 $\mu \mathrm{M}$ in vitro neuronal cell cultures. Furthermore, they reported that within 4 hours after administration of $5-15 \mathrm{mg} / \mathrm{kg}$ cisplatin, edematous swelling examined by electron microscopy and after 24 hours of administration of cisplatin widespread degeneration was observed. Significant central neurotoxicity was observed after a single dose of $5 \mathrm{mg} / \mathrm{kg}$ cisplatin in this study. In the present study, we administered $12 \mathrm{mg} / \mathrm{kg}$ body weight/day cisplatin to the rats for three consecutive days. The histopathological changes including dilated capillaries, vacuolised neurons and increased glial cell in around of neurons were severer in the CS group when compared to CSE group.

The pathogenesis of cisplatin induced neurotoxicity is not clearly understood; however, there is much evidence that production of reactive oxygen species and high levels of Pt-DNA binding and apoptotic cell death of neurons are related. Oxidative stress is strongly associated with neurological disorders because of the high content of polyunsaturated membrane lipid of the central nervous system. It was reported that administration of cisplatin reduces the plasma antioxidant level in the clinical trials on humans ${ }^{29}$. In addition, many previous studies have reported that both short and long term administration of cisplatin causes significant oxidative damage, formation of reactive oxygen species or free radicals in many tissues such as brain, testis, liver, and kidney ${ }^{24,30}$.

Furthermore, experimental animal studies, focused on the role of antioxidants such as vitamin E, vitamin C, erythropoietin, thalidomide, melatonin, alpha lipoic acid, and fish oil, found out that these antioxidant agents are effective in cisplatin toxicities ${ }^{15,31}$. Another possible mechanism of cisplatin-induced neurotoxicity is apoptosis and/or mitochondrial dysfunction. Apoptosis, called as programmed cell death consists of biochemical and histopathological changes leading to morphologic degenerations 
and cell suicide including blebbing, membrane budding, cell shrinkage, nuclear fragmentation, and chromatin condensation. Intracellular apoptotic signaling must induce the regulatory enzymes to initiate the apoptosis pathway. Bax, bak and caspases e.g. enzymes trigger the apoptotic process; however, bcl-2, bcl$\mathrm{xL}$ or mcl-1 family proteins generally act as antiapoptotic which cause delay or inhibition of release of the apoptotic enzymes ${ }^{24}$. In addition, over expression of antiapoptotic proteins provide a true survival advantage in the cells treated with chemotherapeutic agents $^{24}$. Wetzel and Berberich ${ }^{32}$ reported that the cisplatin-induced apoptosis is believed to be the result of DNA damage in surviving cells. Cisplatin binds to the nuclear and mitochondrial DNA of neurons which may trigger the activation of RhoA GTPase, induction of inflammatory pathways ${ }^{32}$. Nuclear DNA damage leads to p53 activation and triggers apoptosis. In the present study, an increase in the bax positive cells and bax/bcl ratio was determined in brains of rats treated with cisplatin when compared to controls. These results demonstrate that the bax activity increase might be correlated with cisplatin induced apoptosis.

Selenium acts as the part of the active site of GPx. GPx is a seleno-enzyme that reduces the mitochondrial stress, reactive oxygen and nitrogen species and protects DNA lipids and protein. Furthermore, selenium has anti-inflammatory properties involving the cyclooxygenase and lipoxygenase cascade and affects cytokine and chemokine expression. It was demonstrated to be effective in cisplatin-induced toxicities, other heavy metal related toxicities and ischemia reperfusion injuries ${ }^{5}$. In this study, selenium treatment before and after cisplatin injection reduced apoptotic neuron and glial cell counts but increased antiapoptotic Bcl-2 activity. These findings suggest that the overexpression pattern of the Bcl-2 protein caused by selenium may be necessary in chemotherapy.

\section{Conclusion}

Selenium may histopathologically and immunohistopathologically prevent cisplatin-induced central neurotoxicity.

\section{References}

1. Desoize B, Madoulet C. Particular aspects of platinum compounds used at present in cancer treatment. Crit Rev Oncol Hematol. 2002;42:317-25. PMID: 12050023.

2. Flore AM, Busselberg D. Cisplatin as an anti-tumor drug: cellular mechanism of activity, drug resistance and induced side effects. Cancer. 2011;3:1351-71. doi: 10.3390/cancers3011351.

3. Chen D, Milacic V, Frezza M, Dou QP. Metal complexes, their cellular targets and potential for cancer therapy. Curr Pharm Des. 2009;15:777-91. PMID: 19275642.

4. Amptoulach S, Tsavaris N. Neurotoxicity caused by the treatment with platinum analogues. Chemother Res Pract. 2011;2011:843019:1-5. doi: 10.1155/2011/843019.

5. Yazici A, Sari ES, Yay A, Aksit H, Kilic A, Aksit D, Yildiz O, Ermis SS. The protective effect of selenium in cisplatin related retinotoxicity. Cutan Ocul Toxicol. 2014;33(4):327-32. doi: 10.3109/15569527.2013.879877.

6. Eken HA, Koç ER, Yazııı H, Yay A, Önder GÖ, Sarıcı SF. Selenium partially prevents cisplatin-induced neurotoxicity: a preliminary study. Neurotoxicology. 2014;19:42C:71-5. doi: 10.1016/j. neuro.2014.04.002.

7. Song TZ, Chen CL, Liao JW, Ou HC, Tsai MS. Ergothioneine protects against neuronal injury induced by cisplatin both in vitro and in vivo. Food Chem Toxicol. 2010;48:3492-9. doi: 10.1016/j. fct.2010.09.030.

8. Ozbal S, Erbil G, Kocdor H, Tugyan K, Pekcetin C, Ozogul C. The effect of selenium against cerebral ischemia-reperfusion injury in rats. Neurosci Lett. 2008;438:265-9. doi: 10.1016/j. neulet.2008.03.091.

9. Chen J, Berry MJ. Selenium and selenoproteins in the brain and brain diseases. J Neurochem. 2003;86 (1):1-12. PMID: 12807419.

10. Ben Amara I, Fetoui H, Guermazi F, Zeghal N. Dietary selenium addition improves cerebrum and cerebellum impairments induced by methimazole in suckling rats. Int J Dev Neurosci. 2009;27(7):71926. doi: 10.1016/j.ijdevneu.2009.07.002

11. Godoi GL, de Oliveira Porciúncula L, Schulz JF, Kaufmann FN, da Rocha JB, de Souza DO, Ghisleni G, de Almeida HL. Selenium compounds prevent amyloid $\beta$-peptide neurotoxicity in rat primary hippocampal neurons. Neurochem Res. 2013;38(11):2359-63. doi: 10.1007/s11064-013-1147-4.

12. Uguz AC, Nazıroglu M. Effects of selenium on calcium signaling and apoptosis in rat dorsal root ganglion neurons induced by oxidative stress. Neurochem Res. 2012;37(8):1631-8. doi: 10.1007/ s11064-012-0758-5.

13. Nowis D, Legat M, Bil J, Kurzaj Z, Issat T, Stoklosa T, Mioduszewska B, Kaczmarek L, Jakobisiak M, Golab J. Erythropoietin reduces cisplatin-induced neurotoxicity without impairment of cytotoxic effects against tumor cells. Int J Oncol. 2007;31:1547-52. PMID: 17982682

14. Kamisli S, Ciftci O, Cetin A, Kaya K, Kamisli O, Celik H. Fish oil protects the peripheral and central nervous system against cisplatininduced neurotoxicity. Nutr Neurosci. 2014;17(3):116-26. doi: 10.1179/1476830513Y.0000000074.

15. Pace A, Savarese A, Picardo M, Maresca V, Pacetti U, Monte GD, Biroccio A, Leonetti C, Jandolo B, Cognetti F, Bove L. Neuroprotective effect of vitamin E supplementation in patients treated with cisplatin chemotherapy. J Clin Oncol. 2003;21(5):92731. PMID: 12610195.

16. Orhan B, Yalcin S, Nurlu G, Zeybek D, Muftuoglu S. Erythropoietin against cisplatin-induced peripheral neurotoxicity in rats. Med Oncol. 2004;21(2):197-203. PMID: 15299192.

17. Rodriguez-Menendez V, Gilardini A, Bossi M, Canta A, Oggioni N, Carozzi V, Tremolizzo L, Cavaletti G. Valproate protective effects on cisplatin-induced peripheral neuropathy: an in vitro and in vivo study. Anticancer Res. 2008;28(1A):335-42. PMID: 18383866.

18. Tuncer S, Dalkilic N, Akif Dunbar M, Keles B. Comparative effects of $\alpha$ lipoic acid and melatonin on cisplatin-induced neurotoxicity. Int J Neurosci. 2010;120(10):655-3. doi: 10.3109/00207454.2010.510916

19. Ajith TA, Abhishek G, Roshny D, Sudheesh NP. Co-supplementation of single and multi doses of vitamins $\mathrm{C}$ and $\mathrm{E}$ ameliorates 
cisplatin-induced acute renal failure in mice. Exp Toxicol Pathol. 2009;61(6):565-71. doi: 10.1016/j.etp.2008.12.002.

20. Erdem T, Bayindir T, Filiz A, Iraz M, Selimoglu E. The effect of resveratrol on the prevention of cisplatin ototoxicity. Eur Arch Otorhinolaryngol. 2012;269(10):2185-8. doi: 10.1007/s00405-0111883-5.

21. Bilginoglu A, Seymen A, Tuncay E, Zeydanli E, Aydemir-Koksoy A, Turan B. Antioxidants but not doxycycline treatments restore depressed beta-adrenergic responses of the heart in diabetic rats. Cardiovasc Toxicol. 2009;9(1):21-9. doi: 10.1007/s12012-0099032-8.

22. Gupta R, Kazmi I, Afzal M, Khan R, Chauhan M, Al-Abbasi FA, Ahmad A, Anwar F. Combination of sulfamethoxazole and selenium in anticancer therapy: a novel approach. Mol Cell Biochem. 2013;384(1-2):279-85. doi: 10.1007/s11010-013-1811-7.

23. Salakou S, Kardamakis D,Tsamandas AC, Zolota V, Apostolakis E,Tzelepi V, Papathanasopoulos P, Bonikos DS, Papapetropoulos $\mathrm{T}$, Petsas $\mathrm{T}$, Dougenis D. Increased $\mathrm{Bax} / \mathrm{Bcl}-2$ ratio up-regulates caspase- 3 and increases apoptosis in the thymus of patients with myasthenia gravis. In Vivo. 2007:21;123-32. PMID: 17354625.

24. Yildirim S, Kisa F, Karadeniz A, Yildirim A, Karakoc A, Can I, Kara A, Simsek N. Effects of pomegranate seed extract on liver paraoxonase and bcl- $\mathrm{x}_{\mathrm{L}}$ activities in rats treated with cisplatin. J Med Plants Res. 2012;6(12):2317-23. doi: 10.5897/JMPR011.788.

25. Brouwers EE, Huitema AD, Boogerd W, Beijnen JH, Schellens JH. Persistent neuropathy after treatment with cisplatin and oxaliplatin. Acta Oncol. 2009;48:832-41. doi: 10.1080/02841860902806609.

26. Krarup-Hansen A, Rietz B, Krarup C, Heydorn K, Rorth M, Schmalbruch H. Histology and platinum content of sensory ganglia and sural nerves in patients treated with cisplatin and carboplatin: an autopsy study. Neuropathol Appl Neurobiol. 1999;25(1):29-40. PMID: 10194773.

27. Rzeski W, Pruskil S, Macke A, Felderhoff-Mueser U, Reiher AK, Hoerster F, Jansma C, Jarosz B, Stefovska V, Bittigau P, Ikonomidou C. Anticancer agents are potent neurotoxins in vitro and in vivo. Ann Neurol. 2004;56(3):351-60. PMID: 15349862.
28. Dietrich, J., Han, R., Yang, Y., Mayer-Pröschel, M., Noble, M. CNS progenitor cells and oligodendrocytes are targets of chemotherapeutic agents in vitro and in vivo. J Biol. 2006;5:22. PMID: 17125495.

29. Weijl NI, Hopman GD, Wipkink-Bakker A, Lenties EG, Berger HM, Cleton FJ, Osanto S. Cisplatin combination chemotherapy induces a fall in plasma antioxidants of cancer patients. Ann Oncol. 1998;9(12):1331-7. PMID: 9932164.

30. Hartmann JT, Kollmannsberger C, Kanz L, Bokemeyer C. Platinum organ toxicity and possible prevention in patients with testicular cancer. Int J Cancer. 1999;83(6):866-9. PMID: 10597214.

31. Amirshahrokhi K, Khalili AR. Thalidomide ameliorates cisplatininduced nephrotoxicity by inhibiting renal inflammation in an experimental model. Inflammation. 2015 Apr;38(2):476-84. doi: 10.1007/s10753-014-9953-7.

32. Wetzel CC, Berberich SJ. p53 binds to cisplatin-damaged DNA. Biochim Biophys Acta. 2001;1517(3):392-7. PMID: 11342217.

\section{Correspondence:}

Ergun Karavelioglu

Afyon Kocatepe Üniversitesi Hastanesi

İzmir yolu 8.km Afyonkarahisar

Phone: +905054546055

ergunkara@hotmail.com

Received: Feb 25, 2015

Review: Apr 24, 2015

Accepted: May 26, 2015

Conflict of interest: none

Financial source: none

${ }^{1}$ Research performed at Laboratory of Animal Unit, Balikesir University, Balikesir, Turkey. 